\title{
The relationship between trait emotional intelligence and entrepreneurship attitudes and intentions
}

\author{
Farzin Farahbod ${ }^{1}$, Mohammadreza Azadehdel ${ }^{1}$, Morad khoshdel Mofidi ${ }^{2^{*}}$, Shahram Shahabi ${ }^{1}$, \\ Habibeh khoshamooz ${ }^{1}$, Laila Doust Pazhouh, Nayereh Ghorbaninejad ${ }^{2}$ and Farzaneh \\ Shadkam $^{1}$ \\ ${ }^{1}$ Public Administration, Department of Management, Islamic Azad University, Rasht Branch, Rasht, Iran. \\ ${ }^{2}$ Business Management, Islamic Azad University, Rasht Branch, Rasht, Iran.
}

Accepted 30 May, 2013

\begin{abstract}
This research intends to evaluate the relationship between trait emotional intelligence and entrepreneurship intentions- with proactivity, creativity and attitudes toward entrepreneurship functioning as mediator variables. The population of the study included 5927- 3784 M.A. students from Guilan University and 2143 from IAU of Rasht. The sample size was defined using Cochran limited sample. 376 questionnaires were distributed, with only 326 completed and returned. This data functioned as the basis for data analysis according to the structure of the model. The results revealed that trait emotional intelligence had a positive relationship with proactivity and creativity. Also, proactivity and attitudes to entrepreneurship had positive relationship with entrepreneurship intentions; meanwhile, variables of creativity, proactivity and trait emotional intelligence as well as the attitudes toward entrepreneurship determined about $55 \%$ of entrepreneurship intentions variable.
\end{abstract}

Key words: Trait emotional intelligence, proactivity, creativity, attitudes toward entrepreneurship, entrepreneurship intentions.

\section{INTRODUCTION}

Nowadays, college and university students have realized that they would ultimately enter diverse, active and complex working environments. Factors such as universality, competition and fast growth of technology have all changed job environments and opportunities. The expectations of entrepreneurs have also changed and they feel the need for employees who express attitudes and tendencies toward entrepreneurship (Zali et al., 2007). Further, evolutions and alterations of socioeconomic systems in the present century have their root in improvement and changes in technological science. Therefore, creativity - creation of new products and services - provides the grounds for survival of countries. Such a phenomenon will not happen unless by those individuals who are able to probe this case through making evolutions and changes in organizations or establishment of new funds. These individuals are referred to as entrepreneurs (Zarini and Dehbani, 2009).

Emergence of entrepreneurship over the globe has turned to a survival source for competitive benefits. It has acted as engine of growth and economic improvement. Post education trains a lot of graduates in many countries to upgrade small businesses since it is difficult to get employed in big organizations (Nabi and Holden, 2008).

The first and most important hypothesis regarding psychological egos of entrepreneurs was stated by McClelland during the 1960s. He states that entrepreneurs are those individuals who feel strong need for 
success and face high risks (Sabaghiyan and Coleagues, 2005).

Modern instances represent the fact that personality and emotional intelligence have great role in the basis of entrepreneurship (Hermann et al., 2007). Findings of modern researches state that the feeling of managers if felt and understood by their employees is effective on satisfaction of employees and on becoming more entrepreneurs (Brundin et al., 2008). Generally speaking, emotional intelligence is effective on entrepreneurs' behavior by two key processes: First, IE is the rater of emotional effectiveness, and individuals who have higher IE have higher patience over environmental pressures (Kamalian and Fazel, 2011). They recognize disappointment feelings better and then regulate their feelings to decrease the pressure, and therefore increase the level of their entrepreneur behavior. Second, IE is a comprehensive process and those who have higher IE have more intention toward higher emotional feelings, creativity and being pioneer in circumstances; and this makes the entrepreneurship behavior easy (ibid, p.134). The point of utmost importance here is that IE plays a role in creation of entrepreneur behavior and those who assess higher IE are more successful in the establishment of new business and trade in a manner that the more entrepreneur an individual becomes, the higher the IE represents itself (Zapetakis et al., 2009).

Entrepreneurship intentions are regarded as preface and effective factors that affect entrepreneur behavior or decision making for becoming entrepreneurs and finding a new business. Further, since timing and schedule plays a key role in opening up a new business, entrepreneur decisions can be considered as part of planned behavior for the prediction of intentions that can be used efficiently (Barani et al., 2010; Krueger, 1993). Entrepreneurship intentions can be defined as 'undertaking to start a new job' (Soleimani and Zarafshani, 2011). IE can guide entrepreneurs in every single step of entrepreneurship. There were many great entrepreneurs who lacked any academic degree but with reliance on their IE could bring about firms with global fame (Kamalian and Fazel, 2011). Petrides and Furnham (2001) as cited in (Siegling, 2010) define IE as "the ability to understand other's feelings and create effective and successful relationship, which has 4 aspects namely: emotionality, self controlling, welfare and sociability" (Well-being, self-control, emotionality, and sociability).

Bateman and Crant (1993) discussed that the index of proactivity might have some impact on choosing a career and on entrepreneurship.

According to specific aspects of proactive personality, theoretical aspects of entrepreneurship are formed. Further, at the time of entrepreneurial opportunities, proactivity expresses a structure among individuals who practice entrepreneurship (Crant, 1996). It also reveals the views of individuals on environment. The subject of entrepreneurship is interwoven with the concept of creativity (Bechere and Maurer, 1999). As Draker (19092005) believes, creativity and entrepreneurship are inseparable; in other words, entrepreneurship is of no value without creativity. Some studies indicate that entrepreneurs follow new jobs or establish new businesses not only for economic purposes but also for the creativity residing in the job itself. For instance, Jeff (1989) surveyed 150 entrepreneurs and found that the initial intention of entrepreneurs was to create something that was new, and the economic interest only played a secondary role (Farid, 2009). The last variable of the present research is, 'the view toward entrepreneurship'. Basically, evaluating the view of individuals can have great impacts on their future activities (Harris and Gibson, 2008).

Today, job challenges and unemployment are deemed as important social issues. Given the amount of growth in such challenges during the last 2 decades, they could rightfully be labeled as the most important social challenge and as the one that will be on the rise during the next few decades. Politicians and decision makers in many countries have faced an array of problems solving this issue. In fact, their ability or inability to remove or diminish the problem has been a determining factor of their governments' survival or expiration. Experts in economy posit that Iran also needs to undergo economic changes to solve its unemployment crisis. This is why, based on published statistics, during the last few years no special movement or improvement has been observed in the country's economic growth. Annually, 800 job seekers enter the market and there are currently more than 10 million unemployed. This was a big challenge in the socio-economic development of the country during the $4^{\text {th }}$ plan and the one after it. The first two idealistic items on the plan for the next 20 years would be to attain the first rank in science and technology in South west of Asia. To attain this goal, some qualitative objectives were set in the $4^{\text {th }}$ plan including improvement of the spirit of working, creativity and entrepreneurship, entrepreneurship development in higher education, implementation of entrepreneurship training programs in Iranian universities as a basic move in the $4^{\text {th }}$ plan (Barani et al., 2010).

Entrepreneurship is an effective method to cope with such problems and to empower the educational system, which has fortunately attained considerable achievements during the recent years (Nazifkar et al., 2010). In Iran, issues related to graduates and their conditions are considered as one of the main predicaments of politicians and educational planners. In general, M.A. students compared to those with a lower degree, have a better chance of being labeled as entrepreneurs because of their higher education and age (Hozuri et al., 2010). The need to provide job opportunities for M.A. graduates in Guilan seems to be more urgent than other provinces since based on official statistics released in 2011, the rate of unemployment in Guilan has mounted to $16.6 \%$, which is the $4^{\text {th }}$ rate after Alborz, Lorestan and Fars 
provinces (Bultannews).

The issue of unemployment and the variables contributing to entrepreneurship view and intention need urgent attention. There is a need to hold entrepreneurship training courses to instigate students to start a business in future. Therefore, the present research aims to discuss the relationship between effective variables on entrepreneurship attitudes and intentions of M.A. students of IAU of Rasht and Guilan University. This topic was chosen since few researches have been done on the topic and a lot more are to be undertaken.

Many entrepreneurship researchers have paid much of their attention onto the process of starting a business and have neglected the decision making issue. This is why decision making proceeds the level of starting a business. The level of decision making discusses what causes an individual to opt for one option rather than others in starting a business.

So, answer to the following questions is sought:

1. Is there a positive relationship between trait emotional intelligence and attitudes towards entrepreneurship and entrepreneurship intentions?

2. Is there a positive relationship between trait emotional intelligence and attitudes towards entrepreneurship and entrepreneurship intentions concerning proactivity?

Nowadays students and graduate students of colleges and universities have well realized that they would ultimately enter diverse, active and complex working environments. Factors such as globalization, competition and rapid growth of technology have changed job opportunities environment. Similarly, the expectations of entrepreneurs have also changed. In fact, they feel the need for employees who reveal attitudes and tendencies toward entrepreneurship. This is why small and mediumsized firms comprise the main bulk of modern businesses. Modern firms have become smaller and big organizations are inclined to recruit less people. In recent years, graduates have shown a lot of zeal to start their own businesses. This implies that we are observing a significant change in employment patterns (Zali et al., 2007).

Basically, human beings are social creatures, and for an individual to be an entrepreneur, owning his business in the society without support and supervision from others seems impossible. In this regard, trait emotional intelligence, the ability to understand and control feelings and emotions of self and others, makes entrepreneurship effective effectiveness (Rahnavard and Jooybar, 2008).

Therefore, different entrepreneurs do not share the same feelings and emotions; they react differently in administration and understanding of opportunities and trait as well recognizing strong and weak points considering the degree of their own emotional intelligence .

Emotional intelligence can be directive for entrepreneurs in every step of entrepreneurship. There existed many great entrepreneurs who did not enjoy high educational intelligence and did not have suitable situation in university but found the greatest firms relying on their emotional intelligence.

This means that those who know that above all mathematical logics, power of inspiration and emotion is functional, and those entrepreneurs who know the scientific structure of the market and inject their own emotional intelligence to it as blood can do wonders. Entrepreneurs who have high emotional intelligence means those who know their own feelings and lead them , can understand other's feelings and lead them as well; they react purposefully towards them and act differently in managing market and therefore are more successful (Kamalian and Fazel, 2011).

Today, thinkers are unanimous about the role of entrepreneurship on economical and social development. The most important of these roles are as follows (Jamshidi and Ghasemi, 2008):

1. entrepreneurship collecting discursive social assets and improves the formation of asset.

2. entrepreneurship causing occupation in broad scale.

3. entrepreneurship decreasing the problem of joblessness which is the core of most economical and social difficulties.

4. entrepreneurship causing balance of logics in society.

5. entrepreneurship causing decrease of economical concentration in society.

6. entrepreneurship causing fare redistribution of wealth , earning and even political powers in society

Moreover, entrepreneurship can be considered as the factor that leads to erection and persuasion of competition, mixing; it, provides the factors of production, factor for arranging the sources and effective use of them , leads to coherence and relation of markets, removes disturbance and grooves and diminishes official bureaucracy.

Therefore by considering the situation of of M.A graduates in Guilan Province like joblessness and analysis of the variables affecting it, entrepreneurship intentions seem necessary and paying attention to this issue can lead to the designing of entrepreneur training program that will encourage students to start a business in future. Therefore, this research aims to discuss the aims and intentions of M.A students of Azad University of Rasht and Guilan University by analyzing the relation affecting the variables. Therefore, we have chosen the relationship between emotional intelligence and entrepreneurship intentions among different variables because a few researches have done on it and so it needs more discussion. Most researchers of entrepreneurship have concentrated on "process of starting a business" and neglected the stage of "decision making "; however the latter step should be prior to the first. In the stage of decision making, individuals pay attention to this question: 'what factors make a person to decide to start a 
business from among all other options?'

An understanding of the factors contributing to entrepreneurship intentions is of vital importance because intentions could be labeled as reliable predictors of entrepreneurship function. The relationship between intention and action has been described by 'the theory of manners' - one of the most general models of predicting function. In this model, intentions play a key role in manners and are further deemed as the medium of attitudes and functions (Zapetakis et al., 2009). Understanding this issue -especially for M.A. students who seek self-employment more than other groups - has a significant impact on economic growth and is, hence, of great importance.

IE is an important factor for success at work. Entrepreneurs are those who perform well above the common people and speedup others in their career; so it seems that IE has significant effects on entrepreneurship (karami et al., 2005).

Present studies have discussed the effect of IE features on attitudes and entrepreneurship intentions; the relationship between IE and proactivity or creativity, and also the relationship between proactivity and creativity. The results they reported show that effective personality is related to effective manners. Bateman and Crant (1993) note that long term probates are needed to create index of effective personality (Ruder, 2003). Creativity is the outcome of new and useful ideas. By attitudes toward entrepreneurship we mean students' understanding of the concept of entrepreneurship (Zapetakis et al., 2009). Regarding factors contributing to selection of entrepreneurship, three trends have already been introduced as follows:

1.Personality based approaches,

2. Demographic based approaches, and

3. Attitudes based approaches.

In this article, attitude was considered since based on researches already undertaken, it is the best predictor for tendency toward entrepreneurship. We believe that attitude is acquired and hence it is possible to change it through training, social environment and job (Bermas et al., 2011).

The hypotheses of this research were as follows:

Attitude toward entrepreneurship circle is based on effective factors -emotional and cognitive factors being its two main elements. Emotional factors are related to feelings and emotions while cognitive factors deal with ideas and thoughts. People with emotional self esteem show higher tolerance toward stress and stressful environmental factors. Such people reveal more stability while facing a problem (Zapetakis et al., 2009). This finding gave way to the first hypothesis of the study:

1. There is a positive relationship between trait emotional intelligence of students and entrepreneurship attitudes. Students with a high degree of El show better potential to resist stress. This leads to a higher level of self esteem. In fact, such people show more zeal to open up a new business and show a higher degree of self esteem and creativity (Zapetakis et al., 2009).

This finding gave way to the second hypothesis:

2. There is a positive relationship between trait emotional intelligence of students and their proactivity. As regard the role of creativity, many articles have already been composed reiterating the relationship between emotional processes and creative results. Accordingly, our presupposition here was that creativity could have an impact on emotional outcomes and that those with a higher degree of IE would show a higher level of creativity (Zapetakis et al., 2009).

Based on this logic and taking the relationship between trait emotional intelligence and creativity, the third hypothesis was formulated as follows:

3. There is a positive relationship between trait emotional intelligence of students and their creativity.

Zampeakis and Moustakis (2006), in their recent study, asserted that creative self esteem of engineering students could predict the increasing layers of entrepreneurship intentions. This shows that the relationship between creativity and entrepreneurship intentions can even be closer than earlier thought. However, more research needs to be undertaken before we can make any type of generalization about such findings (Zapetakis et al., 2009). Based on our previous discussion, the following hypotheses were formulated:

4. There is a positive relationship between proactivity of students and their entrepreneurship attitudes.

5. There is a positive relationship between students' creativity and their entrepreneurship attitudes.

Binnewies et al. (2007) suggest that individual's creativity is important at the beginning of a creative process (Zapetakis et al., 2009). Based on this logic, the following hypothesis was stated:

1. There is a positive relationship between entrepreneurship attitudes of students and their entrepreneurship intentions. Taking the general differences between pre and post variables, we conceptualized IE as a far range concept. As a far range variable, IE affects entrepreneurship intentions through backgrounds close to the source (Zapetakis et al., 2009,p601).

Based on this idea, we hypothesized that:

2. There is an indirect relationship between trait 


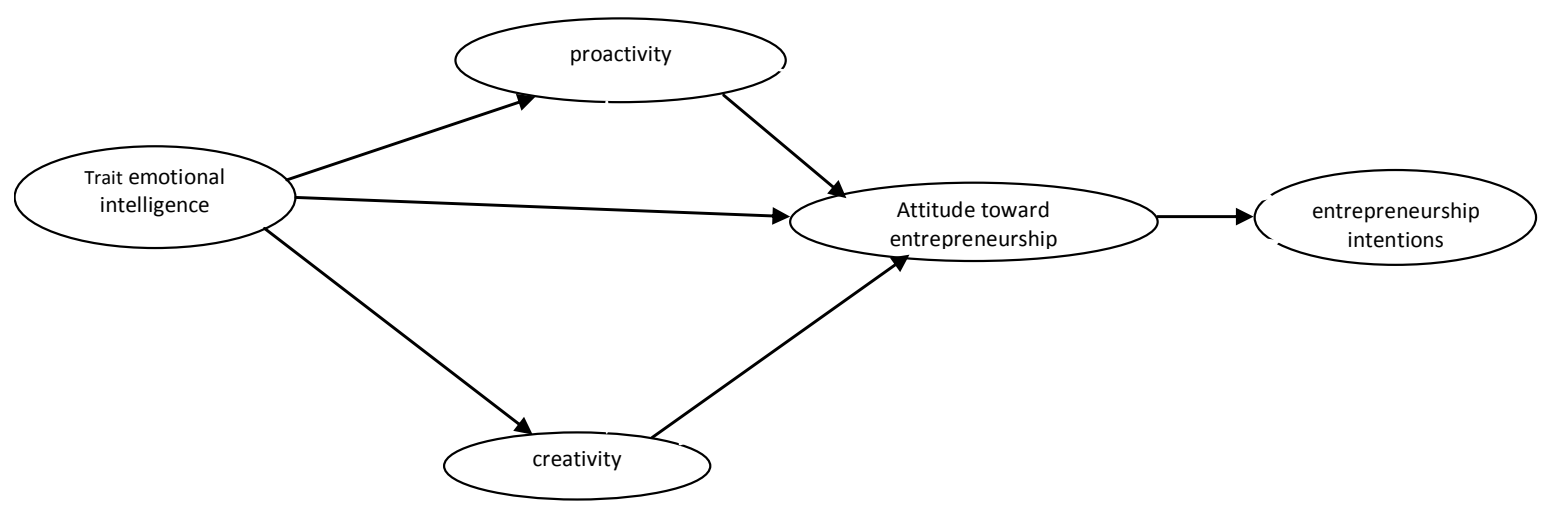

Figure 1. Representation of the theoretical model (Zapetakis et al, 2009).

emotional intelligence and entrepreneurship intentions. 3 . There is a relationship between creativity and proactivity of students with entrepreneurship intentions noting their entrepreneurship attitudes.

According to the aforementioned items, the present research aims to study factors affecting entrepreneurship on the basis of the following model (Figure 1).

\section{METHODOLOGY}

The present study is a descriptive-analytical research. In all, 5927 M.A. students from IAU of Rasht and Guilan University formed the population of this research -3784 students from Guilan University and 2143 students from IAU of Rasht. From this population, Cochran limited society method was used to set the total sample size. 370 questionnaires were distributed; only 326 of them were completed by the participants and collected. From this number, 118 were from IAU of Rasht and 208 were from Guilan University. In this research, data collection was undertaken by survey method and the tool used was questionnaire.

Questionnaire was drawn to collect the data required to test hypothesis 5 . To measure trait emotional intelligence, a brief 3oitem questionnaire (TEQE-SE) ${ }^{1}$ designed by Petradaise and Farenhaeim (2001) was used. Along with the 30 questions, the questionnaire also included 15 distracters. TEQE-SF brings about the high possibility of trait emotional intelligence with high credit (Zapetakis et al., 2009). Petradise and Farenhaeim (2001) concluded that 4 factors - welfare, self control, emotionality and sociality - should be organized (Zapetakis, 2011). To assess proactivity, the brief 6-item questionnaire by Bateman and Crant (1993) was utilized. This questionnaire evaluates different aspects of proactivity function including active personality and degree of useful changes of the environment (Crant, 1996). Creativity was also measured by the 13- item questionnaire of Zhou and George (2001). This questionnaire evaluated the production of new and useful ideas and solutions. Within the functional description, the attitude toward entrepreneurship was evaluated by 2 questions:

1. Is the idea of just being an entrepreneur more interesting to me? 2. Do I intend firmly to become an entrepreneur?

Regarding the dependent variable, entrepreneurship intention and

\footnotetext{
1. Trait Emotional Intelligence Questionnaire.
}

based on Krueger's (1993) description, two questions were drawn on:

1. Do I intend to start my own business in future?

2. Do I intend to work hard for my future business?

Comparison of level medium among the two groups of male and female showed that there is a meaningful relationship between them in the variable of creativity. And creativity is more in males. The earning condition of students was not considered.

There were no significant differences in other variables

\section{Testing the hypotheses}

Here, hypotheses of the study will be tested. To accept or reject a hypothesis, the structural model at its standard version in numerical meaningfulness was used. If the t-value is between $-1.96 \&+1.96$ the hypothesis is rejected; otherwise, it is confirmed (Table 1).

H7. Trait emotional intelligence has indirect relationship with entrepreneurship intentions.

Within the structural model of the research - and after analysis of the relationships between hidden variables - three paths from trait emotional intelligence to entrepreneurship intentions were observed to be meaningful. The effect of trait emotional intelligence on entrepreneurship intention was determined by multiplying the three paths and summing up the results as illustrated as follows:

$0.095=0.74^{*} 0.18^{*} 0.72$

$0.340=0.74^{\star} 0.63 * 0.73$

$0.340+0.095=0.435$

To test hypothesis 8 , it was first divided into two parts namely $\mathrm{H} 8 \mathrm{~A}$ and $\mathrm{H} 8 \mathrm{~B}$.

H8a: There is a positive relationship between creativity and entrepreneurship intentions considering entrepreneurship attitudes. Since the relationship between creativity and entrepreneurship attitudes and also that between entrepreneurship attitudes and intentions are positive and meaningful, it can be concluded that creativity affects entrepreneurship intentions through entrepreneurship attitudes. The amount of this impact is computed as follows: $0.63^{\star} 0.74=0.466$.

H8b: There is a positive relationship between proactivity and entrepreneurship intentions considering entrepreneurship attitudes. Since the relationship between proactivity and entrepreneurship 
Table 1. Results of testing the hypotheses.

\begin{tabular}{|c|c|c|c|}
\hline Hypothesis & sd & $t$ & results \\
\hline $\begin{array}{l}\text { H1. There is a positive relationship between students' trait emotional } \\
\text { intelligence and their entrepreneurship attitudes. }\end{array}$ & -0.51 & -0.05 & rejected \\
\hline $\begin{array}{l}\text { H2. There is a positive relationship between trait emotional intelligence of } \\
\text { students and their proactivity. }\end{array}$ & 8.53 & 0.72 & confirmed \\
\hline $\begin{array}{l}\text { H3. There is a positive relationship between trait emotional intelligence of } \\
\text { students and their creativity. }\end{array}$ & 11.97 & 0.73 & confirmed \\
\hline $\begin{array}{l}\text { H4. There is a positive relationship between students' proactivity and their } \\
\text { entrepreneurship attitudes. }\end{array}$ & 2.07 & 0.18 & confirmed \\
\hline $\begin{array}{l}\text { H5. There is a positive relationship between students' creativity and their } \\
\text { entrepreneurship attitudes. }\end{array}$ & 7.43 & 0.63 & confirmed \\
\hline $\begin{array}{l}\text { H6. There is a positive relationship between students' entrepreneurship } \\
\text { attitudes and their entrepreneurship intentions. }\end{array}$ & 12.66 & 0.74 & confirmed \\
\hline
\end{tabular}

attitudes as well as between entrepreneurship intentions and attitudes is positive and meaningful, it can be concluded that proactivity affects entrepreneurship intentions through entrepreneurship attitudes. The amount of this impact was measured as follows: $0.18^{\star} 0.74=0.133$.

\section{Discussing structural equations of the model}

ENTR.INT $=0.70 *$ ATTTOENT, Errorvar $.=0.55, \mathrm{R}^{2}=0.55$.

The above equation indicates that variables of creativity, proactivity and entrepreneurship attitudes determine about $55 \%$ of the variable of entrepreneurship attitudes.

ATTTOENT $=0.70^{*}$ CREATIVI $+0.15^{\star}$ PROACTIV $0.061^{\star}$ EM.INTEL, Errorvar. $=0.71, \mathrm{R}^{2}=0.50$.

Based on the above equation, the variables of creativity, proactivity and trait emotional intelligence determine about $50 \%$ of the variable of entrepreneurship attitudes.

Given the structural equations of the model and the obtained ratios, it can be concluded that the model is able to properly determine and predict the final dependant variables of the research, that is entrepreneurship intentions.

\section{DISCUSSION AND CONCLUDING REMARKS}

Individuals are not alike in emotional intelligence capabilities. Golman believes that the emotional ability of individuals is their neurological system. These abilities represent the collection of habits and their reactions; their depletion could be recovered by training and effort. Most neurologists believe that $50 \%$ of emotional intelligence of individuals is formed at birth and is not changeable. On the other hand, they believe that many efforts can be put to the rest $50 \%$.

As Mayer states, emotional intelligence is a mental capacity for giving meaning and function of emotional information. Individuals have different capacities: some at medium level and some are experts. A part of this capacity is innate and the others come from experience. The latter could be improved by effort and training. Salovy also states that most skills which are a part of emotional intelligence could be improved by counseling, preparation and skill training (Labaf et al., 2011).

Findings revealed that trait emotional intelligence holds relationship with entrepreneurship attitudes and intentions. This relationship is, however, indirect and proactivity and creativity are its media. It was further observed that students with higher trait emotional intelligence can create proactivity by resisting stress and developing positive emotions. Also, the relationship between trait emotional intelligence and creativity and attitudes was also proved. So, entrepreneurs facing stress reveal higher self confidence and more flexibility. Based on the findings of the study, entrepreneurship trainers and politicians should be encouraged to improve entrepreneurship intentions among university students. Based on the study, the following suggestions could be made:

Since hypotheses 2, 3 and $7-\mathrm{H} 2$ (there is a positive relationship between trait emotional intelligence and proactivity), $\mathrm{H} 3$ (there is a positive relationship between trait emotional intelligence and students creativity) and $\mathrm{H} 7$ (The indirect relationship between trait emotional intelligence and entrepreneurship intention was meaningful) - were accepted, the following points could be made:

Since compared to other questions on the trait emotional intelligence questionnaire, the question "I believe everything in my life is going well" has the lowest me-dium, it is suggested that trait emotional intelligence be increased through counseling and, of course, life skill training. This will certainly increase and strengthen emotional ability, self control, sociability and welfare. 
Based on hypotheses 5 and $8-\mathrm{H} 5$ (There is a positive relationship between students' creativity and their entrepreneurship attitudes), H8 (There is a positive relationship between creativity and entrepreneurship intentions) - and taking into account the entrepreneurship attitudes observed, the following suggestions could be made:

Since from among the questions related to creativity, the question "Am I full of noble ideas?" received the lowest medium, it is suggested that the ego for mental features, curiosity, putting forward innovative ideas, paying attention to details, critical spirit, interest in experimentation and positive attitudes toward entrepreneurship be strengthened through creating intentions, proper environment and proper training.

Due to acceptance of hypothesis 6 - There is a positive relationship between entrepreneurship attitudes and entrepreneurship intentions - the following suggestions could be made:

Since the medium score obtained for the question "D I seriously intend to become an entrepreneur" was low, it is suggested that this phase be improved by presenting entrepreneurship courses and training could cause positive attitudes among the students toward entrepreneurship.

\section{1. it is better to take students income into consideration in} future researches.

2. since the norms of the society are placed in the culture of the society and culture affects entrepreneurship if the norms and entrepreneurship activities are directed towards supporting entrepreneurship in cultural dimension, therefore it is suggested that the culture of the society be placed as effective variable in next researches .

3. in the same research done in Greece in 2009 all hypothesizes were confirmed except hypothesis 5 which was the positive relationship between creativity of students, and their attitude was rejected.

4. it is suggested that other methods be used in future researches .

5 . to be certain of the results of these researchers it is better that similar researches be done in other countries .

\section{REFERENCES}

Bateman TS, Crant JM (1993). The proactive component of organizational behavior. J. Organ. Behav., 14:103-118.

Barani Sh, Zarafshani K, Deangizan S, Hosseini Lorgani SM (2010). The effect of entrepreneurship training on entrepreneurial manner of students of Kermanshah PNU, Q. Res. Plann. Higher Educ. 57:85105.

Bermas H, Mehrabi R, Hosseini Asli F (2011). Analyzing the effect of job counseling on changing attitude and increasing the entrepreneurial manner and creating jobs for students, Quarterly Latest News on Industrial/Organizational Psychology 2(7):87-95.
Brundin E, Patzelt H, Shepherd DA (2008). "Managers' Emotional Displays and Employees' illingness to Act Entrepreeurially", J. Bus. Venturing (23):221-243.

Bultannews, Retrieved April 15, 2012 fromwww.bultannews.com.

Bechere RC, Maurer JG (1999). The Proactive Personality Disposition and Entrepreneurial Behavior among Small Company Presidents, J. Small Bus. Manage. pp.28-36.

Crant JM (1996). The proactive personality scale as a predictor of entrepreneurial intentions. J. Small Bus. Manage. 34(3):41-48.

Farid D (2009). Discussing the relationship between creativity and entrepreneurship among athletes and non-athletes men and women. Sports Manage. 2:97-116.

Hozuri M, Alipour A, Didab S (2011). Relationship between cognitive method of Gerigoric with entrepreneurial features of M.A. students $f$ PNU, Entrepr. Dev. 3(12):125-144.

Harris ML, Gibson SG (2008). Examining the entrepreneurial attitudes of US business students. Educ. Training 50(7):568-581.

Hermann F, Manfred L, Christian K (2007). "The Significance of Personality in Business Start-up Intentions, Start-up Realization and Business Success", Entrepr. Regional Dev. 19(3):227-251.

Kamalian A, Fazel A (2011). Discussing the relationship between IE and students entrepreneurship. Entrepr. Dev. 3(11):127-146.

Jamshidi K-H, Ghasemi M (2008). Entrepreneurship; concepts, roles and skills, Entrepreneur Association of Qom Tehran University campus (1):55-72.

Karami A, Bahrami F, Maghsudi J (2005). IE, the lost ring of entrepreneurship. Rooyesh Q. 3(12):39-53.

Labaf H, Esmaeel AM, Masoodi M (2011). Emotional Intelligence and its importance in organizational success, J. Hum. Dev. Policy 8(36):6287.

Nabi G, Holden R (2008). Introduction graduate entrepreneurship: intentions, education and training, 50(7):545-551.

Nazifkar S, Ahmadpur Daryani M, Karimi A (2010). Evaluating and analyzing the obstacles in entrepreneurship development in higher education system of applied science of agriculture and natural resources. Q. Agric. Training Manage. Res. (15):31-43.

Rahnavard F, Jooybar M (2008). Comparison of emotional intelligence between the three levels of management._Manage. Message (26): $101-118$

Ruder GJ (2003). "The relationship among organizational justice,trust, and role breadth self-efficacy", Dissertation submitted to the faculty of the Virginia Polytechnic Institute and State University in partial fulfillment of the requirements for the degree of Doctor Of Philosophy in Human Development, Albert W, Gabriella B, Marcie B, Norman E, Linda M, With College Graduates pp.1-142.

Siegling $A B$ (2010). Relations of Emotional Intelligence with GenderLinked Personality and the Big Five, A Thesis submitted to the faculty of graduate studiesin partial fulfilment of the requirements for thedegree of master of science, Faculty of Education, Calgary, Alberta pp.1-33.

Sabaghiyan Z, Ahmadpour M, Azizi M (2005). Discussing the entrepreneurship features among students. Manage. Message 13\&14L163-190.

Zapetakis LA, kafetsios K, Bouranta N, Dewitt T, Moustakis VS (2009). On the relationship between emotional intelligence and entrepreneurial attitudes and intentions. J. Behav. Res. 15(6):595618.

Zapetakis LA (2011). "Resesrch on emotin inorganization", emrald group publishing limited(www.emeraldinsight.com) pp.289-315.

Zali M, Madhooshi M, Kordnaeej A (2005). Evaluating the features of students entrepreneurship. Modarres Q. 55:81-112.

Zarini E, Dehbani R (2009). Entrepreneurship. Noor-eElm, 1. 